\title{
Erythropoietin acts as a trophic factor in neonatal rat intestine
}

\author{
S E Juul, D J Ledbetter, A E Joyce, C Dame, R D Christensen, Y Zhao, V DeMarco
}

\begin{abstract}
Background-Erythropoietin (Epo) receptors are present on enterocytes of fetal and neonatal small bowel but the role of Epo in the bowel is not known.

Aims-We tested the following hypotheses: (1) enterally dosed Epo is absorbed from the intestines of neonatal rats, (2) Epo acts as a trophic factor in developing small bowel, and (3) the trophic effects of Epo are dependant on the route of administration.

Methods-The dose dependant effects of enterally dosed recombinant human erythropoietin (rEpo 0-1000 U/kg/day) were studied in artificially raised rat pups and compared with dam raised controls and dam raised pups given rEpo in rat milk. After one week, reticulocyte counts, haematocrits, and plasma Epo concentrations were measured, and calibrated morphometric measurements of villi were performed. The effects of route of rEpo administration (enteral $v$ parenteral) on erythropoiesis, bowel growth, and disaccharidase activity were studied in nursing pups treated for one and two weeks.

Results-Serum Epo concentrations ranged from undetectable $(<0.6 \mathrm{mU} / \mathrm{ml})$ to $8.4 \mathrm{mU} / \mathrm{ml}$ in control and enterally dosed pups (median $1.8 \mathrm{mU} / \mathrm{ml}$ ), and from 4.9 to $82.3 \mathrm{mU} / \mathrm{ml}$ (median $20.4 \mathrm{mU} / \mathrm{ml}$ ) in parenterally dosed animals. No increase in haematocrit or reticulocyte count was noted in enterally treated pups compared with controls after up to two weeks of treatment. Small bowel length was greater in rEpo treated pups, and a dose dependent increase in villus surface area which was independent of the route of dosing and associated with increased BrdU uptake was found.
\end{abstract}

Conclusions-rEpo is not enterally absorbed in an intact and functional form from the intestines of neonatal rat pups. Thus enterally dosed rEpo has no erythropoietic effects. However, rEpo acts as a trophic factor in developing rat small bowel whether given enterally or parenterally.

(Gut 2001;49:182-189)

Keywords: erythropoietin; enterocytes; breast milk; development; neonate; rat

Erythropoietin (Epo) is present in human milk $^{12}$ but its physiological function in the developing intestine is not known. During fetal life, enterocytes are exposed to Epo contained in swallowed amniotic fluid, ${ }^{34}$ and in breast fed infants exposure to enteral Epo continues in mother's milk. ${ }^{1256}$ We previously reported the presence of Epo receptors (Epo-R) in intestinal villi of developing humans and rats. ${ }^{78}$ These Epo receptors appear to be functional, as recombinant Epo (rEpo) increases IEC 6 cell migration, decreases apoptotic death following damage, and has trophic effects on cultured gastric mucosal cells. ${ }^{89}$ Thus Epo-R are present on enterocytes, the receptor is functional, and a readily accessible source of its ligand is available to the fetus and breast fed neonate. Possible physiological roles of Epo in the developing gut include: (1) systemic erythropoietic effect following Epo absorption, and (2) local effects.

It is not known if rEpo must be applied locally (enteral dosing) or whether systemically administered rEpo might have effects in the developing bowel. Two studies support the hypothesis that systemic Epo may have important effects in bowel: rats treated with parenteral rEpo prior to a surgical anastomosis showed improved healing, with increased strength of the anastomosis, ${ }^{10}$ and secondly, in a retrospective study of infants $\leqslant 1250 \mathrm{~g}$ who received $\mathrm{rEpo}$ for anaemia of prematurity, the incidence of necrotising enterocolitis was lower $(4.6 \%$ v $10.8 \% ; \mathrm{p}<0.05)$ compared with infants who did not receive rEpo. ${ }^{11}$

Our objectives for this study were to test the following hypotheses: (1) enterally dosed Epo is absorbed from the intestines of neonatal rats in a form that is recognised by ELISA and stimulates erythropoiesis in the animal, (2) Epo acts as a trophic factor in developing small bowel, and (3) the trophic effects of Epo are not dependant on its route of administration.

Materials and methods

ANIMAL INSTRUMENTATION

All animal experiments were approved by the animal use committee of the University of Florida. Five day old Sprague-Dawley rat pups (11.4 (1.1) g, mean (SD)) (Charles River, Inc, Charleston, South Carolina, USA) were briefly anaesthetised with methoxyflurane until loss of righting reflex was noted. A percutaneous gastrostomy tube (PE-10 tubing) was then inserted. ${ }^{12-14}$ The exteriorised portion of the cannula was secured in place by passing the tubing under a fold of skin on the neck.

Abbreviations used in this paper: $\mathrm{BrdU}$ bromodeoxyuridine; Epo, erythropoietin; Epo-R, erythropoietin receptor; rEpo, recombinant human erythropoietin; RMS, rat milk substitute. 
ARTIFICIAL REARING

The cannulae were connected to $12 \mathrm{ml}$ syringes containing chilled $\left(7^{\circ} \mathrm{C}\right)$ rat milk substitute (RMS) mounted on a computerised syringe pump apparatus (model 22 syringe Pimp; Harvard Apparatus, Boston, Massachusetts, USA). Rats were kept individually in $454 \mathrm{~g}$ containers containing dust free maize cob bedding. These were floated in large capacity water baths maintained at $40^{\circ} \mathrm{C}$. Rats were fed RMS for 20 minutes every hour. Because of the small diameter of the cannulae and the length of tubing between the refrigerator and the pups (approximately $1 \mathrm{~m}$ ), the RMS equilibrated to room temperature by the time the RMS entered each pup's stomach. Cannulae were flushed daily with sterile saline to insure patency. Rat pups were weighed and stimulated to micturate and defecate daily.

RAT MILK SUBSTITUTE (RMS)

A formula has been developed which mimics the macro- and micronutrient content of rat's milk and promotes normal metabolic and developmental events for artificially reared rat pups. ${ }^{13}$ RMS contains no Epo, but when rEpo is added, over the concentration range we employ in the infusions, it is stable for a 24 hour period, as judged by ELISA measurements. The volumes of milk infused per day (approximately $230 \mathrm{ml} / \mathrm{kg} /$ day on day 5 of life increasing to $370 \mathrm{ml} / \mathrm{kg} /$ day on day 12) varied according to the average weight of pups within a treatment group, and was calculated daily.

\section{EXPERIMENTAL CONDITIONS}

Experiment 1

Group $1(n=21)$ received RMS containing only saline additive. Group $2(n=11)$ received RMS containing a daily dose of $200 \mathrm{U} / \mathrm{kg} \mathrm{rEpo.}$ Group $3(n=19)$ received RMS containing a daily dose of $1000 \mathrm{U} / \mathrm{kg}$ rEpo. Groups 4 and 5 were sham operated (anaesthetised, and PE-50 inserted into stomach but no perforation) and returned to their dams, treated with either intraperitoneal saline injections (group 4, $\mathrm{n}=20$ ) or intraperitoneal $\mathrm{rEpo} 200 \mathrm{IU} /$ day (group 5, $n=18$ ). After seven experimental days, rats were given an overdose of pentobarbital intraperitoneally. Blood was withdrawn from the right ventricle into a heparinised syringe. After withdrawing an aliquot for determination of haematocrit and reticulocyte count, plasma was separated and stored for Epo ELISA. The animals were perfusion fixed by inserting a needle into the left ventricle, cutting the right auricle, and flushing with phosphate buffered saline until clear, followed by a $4 \%$ paraformaldehyde infusion. The entire small bowel was removed, weighed, and the length from stomach to ileocecal valve measured. Each animal had a $5 \mathrm{~cm}$ segment, removed $4 \mathrm{~cm}$ distal to the distal end of the stomach, paraffin embedded for histological evaluation.

Manual expression of rat milk

To determine Epo concentrations in milk from dams treated with rEpo, measurements were made at timed intervals following single or multiple injections of $200 \mathrm{U}$ rEpo intraperitoneally. Rat dams were lightly anaesthetised with pentobarbital $(0.1-0.2 \mathrm{mg} / \mathrm{kg}$ intraperitoneally) and then given oxytocin (4 U/kg intraperitoneally) to stimulate milk let down. Milk was then manually expressed. Between 1 and $1.5 \mathrm{ml}$ milk were obtained per milking. ${ }^{15}$

\section{Experiment 2}

To determine if the effects of Epo in bowel were route dependent (enteral $v$ parenteral), a second model was employed: for each experiment, Sprague-Dawley rats from three litters were delivered and mixed, such that the average weight of all pups was the same in each group. On day 5 of life, three groups were formed ( $n=10-12 /$ group/experiment). The group 1 dam received a daily injection of sterile saline $200 \mu \mathrm{l}$ intraperitoneally (controls). The group 2 dam received a daily intraperitoneal injection of $200 \mathrm{U} \mathrm{rEpo}$; thus pups in this group were exposed to rEpo excreted into the dam's milk. In the third group, each pup received a daily dose of $200 \mathrm{U} / \mathrm{kg} /$ day subcutaneous rEpo. Pups continued to suckle as usual. Experiments were carried out for either seven or 14 days. At the time of sacrifice, blood was drawn by cardiac puncture for measurement of haematocrit and reticulocyte counts, and plasma was separated and stored for Epo ELISA. The entire small bowel was removed, weighed, and the length from stomach to ileocaecal junction measured. Each animal had a $4 \mathrm{~cm}$ segment from the proximal duodenum, mid jejunum, and terminal ileum paraffin embedded for histological evaluation.

Epo ASSAY

Epo concentrations in plasma and milk were assayed using the Quantikine IVD human Epo Immunoassay ELISA (R\&D Systems, Minneapolis, Minnesota, USA). Spiking experiments were done, adding rEpo to rat milk, to ensure reliability of the assay when using milk. Consistent quenching was seen when milk samples were measured such that approximately $70 \%$ of the added rEpo was measured. Variability was less than $10 \%$ and sensitivity $0.6 \mathrm{mU} / \mathrm{ml}$. This assay has been tested for cross reactivity with other cytokines, and the specificity of the assay is greater than $98 \%$.

MORPHOMETRIC MEASUREMENTS

Ten digitised images each from the duodenum, jejunum, and ileum were evaluated from each animal using the calibrated Analytical Imaging System (Imaging Research Inc, St Catharines, Ontario, Canada). Images from the attached light microscope were digitised at $25 \times$ magnification. An investigator blinded to the treatment group measured the number of villi $/ \mathrm{mm}$ bowel wall, villus length, diameter, area, and crypt depth for each digitised image. Images were digitised only if they had a minimum of six measurable intact villi in the field.

\section{DISACCHARIDASE ACTIVITY}

A subset of animals were not perfusion fixed $(n=21)$. After measurements of their bowel were made, weighed segments of duodenum, 
jejunum, and ileum were homogenised in $0.010 \mathrm{M} \mathrm{NaH} \mathrm{PO}_{4} / \mathrm{Na}_{2} \mathrm{HPO}_{4}, \mathrm{pH}$ 6.0, containing $0.002 \%$ Triton X-100 for later evaluation of disaccharidase activity. The following maltose, sucrose, and lactose solutions were used as substrate for maltase, sucrase, and lactase activity, respectively: $0.0156 \mathrm{M}$ mal-

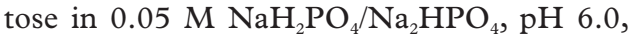
$0.04 \mathrm{M}$ sucrose in $0.05 \mathrm{M} \mathrm{NaH}_{2} \mathrm{PO}_{4} /$ $\mathrm{Na}_{2} \mathrm{HPO}_{4}, \mathrm{pH} 6.0$, and $0.0 .188 \mathrm{M}$ sucrose in $0.05 \mathrm{M} \mathrm{NaH} \mathrm{PO}_{4} / \mathrm{Na}_{2} \mathrm{HPO}_{4}, \mathrm{pH}$ 6.0. A glucose standard curve ranging from 0 to 200 $\mu \mathrm{M}$ was prepared. After incubating an aliquot of test homogenate with each solution for 30 minutes at $37^{\circ} \mathrm{C}$, cold Trinder reagent (Sigma) was added to all tubes, including the standard curve samples. After incubation at $37^{\circ} \mathrm{C}$ for 30 minutes, absorbance at $505 \mathrm{~nm}$ was measured.

DETERMINATION OF CELL TURNOVER IN VILLI

A subset of animals $(n=24)$ received timed injections of bromodeoxyuridine (BrdU 50 $\mathrm{mg} / \mathrm{kg}$ ) intraperitoneally two hours prior to death, and were perfusion fixed with $4 \%$ paraformaldehyde infusion. Segments $(2 \mathrm{~cm})$ were cut from the proximal duodenum, mid jejunum, and distal ileum. Tissue was fixed overnight in $4 \%$ paraformaldehyde, changed to $80 \%$ alcohol, and paraffin embedded. Sections $(4 \mu \mathrm{m})$ were placed on poly-L-lysine coated slides and dried for two hours at $60^{\circ} \mathrm{C}$. After deparaffinisation in two xylene washes, and rehydration through a graded series of alcohols, finishing with water, tissues were quenched in $3 \% \mathrm{H}_{2} \mathrm{O}_{2}$ and permeabilised with trypsin. Biotinylated mouse anti-BrdU was then applied, with streptavidin-peroxidase, and diaminobenzidine used for visualisation, as directed by the BrdU staining kit (HC524) from Oncogene (Boston, Massachusetts, USA). Haematoxylin was used as a counterstain. To determine the percentage of crypt cells which were BrdU positive, three fields per bowel segment were counted at $400 \times$ for each specimen. Only fields in which at least one positive crypt cell was present were chosen. All crypt cells in the field were counted and designated either positive or negative.

STATISTICAL ANALYSIS

The Student's $t$ test with Bonferroni correction for multiple comparisons was used to compare morphometric parameters. Variables measured repeatedly within a subject were averaged for the correlation analysis. All tests were two sided and tested at an alpha value of 0.05. Spearman rank correlations were used to examine linear and non-linear associations between Epo concentrations in milk and serum. Values are reported as mean (SEM) unless otherwise stated.

\section{Results}

ARTIFICIALLY RAISED PUPS AND NURSING CONTROLS

After one week of therapy, serum Epo concentrations were not different between the three groups of artificially raised pups, or nursing control pups (fig 1A). Similarly, reticulocyte counts and haematocrits were not different between groups (fig 1B). Weight gain in the artificially reared pups was consistently lower than in the nursing control pups. However, there were no differences in weight gain between the three artificially reared groups.

Epo concentrations in RMS were measured before and after refrigeration for 24 hours. Epo concentrations were undetectable, 371 (18) $\mathrm{mU} / \mathrm{ml}$, and 4338 (425) $\mathrm{mU} / \mathrm{ml}$ in control, low dose, and high dose RMS, respectively. No differences were noted before and after refrigeration for 24 hours. Serum and milk Epo concentrations were measured in dams from groups 4 and 5 after seven days of treatment. Haematocrits of the rEpo treated dams were high, ranging from $72 \%$ and $76 \%$ versus $37 \%$ to $44 \%$ in control dams. Epo concentrations in rat milk were dependent on the proximity of the testing to rEpo dosing. Mean milk Epo concentration after intraperitoneal injection was 68.9 (24.9)
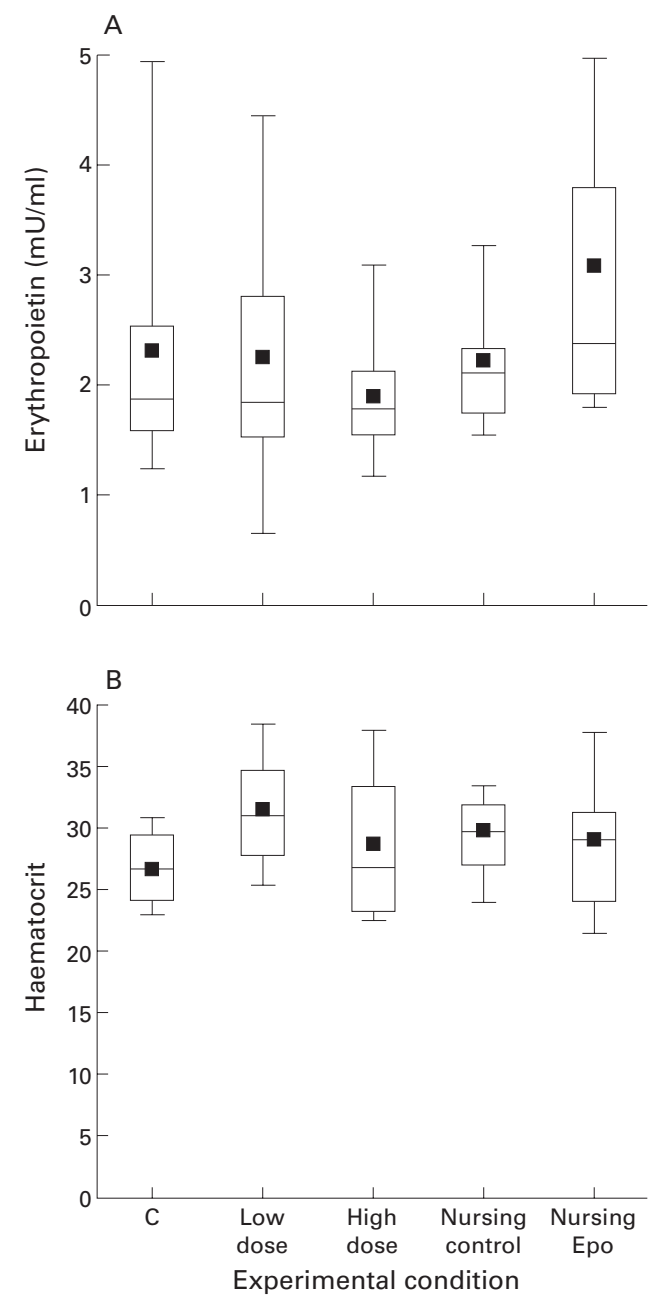

Figure 1 Erythropoietin (Epo) concentrations and haematocrit values from artificially raised and nursing rat pups. (A) Epo concentrations in the different treatment groups. The first three groups were artificially raised and received exogenous recombinant human erythropoietin (rEpo) as follows: control (C), 0 U/kg/day; low dose, 200 U/kg/day; and high dose, $1000 \mathrm{U} / \mathrm{kg} /$ day. The nursing control pups received no exogenous rEpo while the nursing Epo treated group received rEpo contained in mothers' milk. The top, bottom, and line through the middle of the box plot indicate the $75 \mathrm{th}, 25 \mathrm{th}$, and 50 th percentiles (median), respectively. The whiskers on the bottom extend from the 10th to the 90 th percentiles. Mean values for each group are denoted by the filled box. (B) Haematocrit values in the treatment groups defined above. 


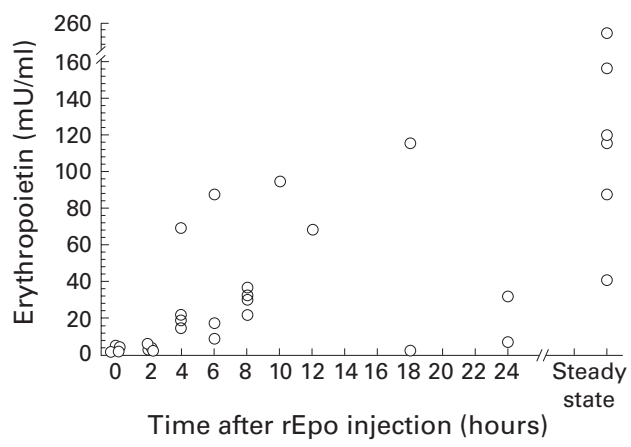

Figure 2 Erythropoietin (Epo) concentrations in rat milk following timed recombinant human erythropoietin ( $r E p o$ ) injection. Epo concentrations ( $\mathrm{mU} / \mathrm{ml}$ ) are shown versus time after a single injection of $200 \mathrm{U}$ rEpo intraperitoneally. The right hand side of the $X$ axis shows Epo concentrations drawn 24 hours after the last dose of $r$ Epo to animals that had received daily doses of $200 \mathrm{U}$ rEpo intraperitoneally for seven days.

$\mathrm{mU} / \mathrm{ml}$ (range 1.2-256); mean serum Epo concentration was $746.9(252.5) \mathrm{mU} / \mathrm{ml}$ (range 16.5-2200). The correlation coefficient for milk versus serum Epo was $r^{2}=0.522$. Milk Epo concentrations after a single injection, and 24 hours after seven days of daily injections (steady state) are shown in fig 2.

Mean bowel length in the high dose group was 42.7 (3.1) $\mathrm{cm}$ while in control pups it was $40.4(0.6) \mathrm{cm}(\mathrm{p}=0.09)$. Pups which had suckled from the rEpo treated dam had an average bowel length of $52.2(0.8) \mathrm{cm}$ while control pups had an average bowel length of 47.7 (1.3) $\mathrm{cm}(\mathrm{p}<0.02)$. There were no significant differences in body weight between the rEpo and control pups.

We next evaluated the bowel of rEpo treated rats compared with controls by light microscopy. Enterally dosed rEpo increased villus surface area of the proximal jejunum in a dose dependent manner. Table 1 shows computer calibrated measurements of villi for the artificially reared pups and nursing pups. Enteral rEpo had a trophic effect on small bowel villi (proximal jejunum) whether given in RMS or in mothers' milk, increasing villus surface area, length, and villus density (number of villi $/ \mathrm{mm}$ of bowel wall). We observed no effect of rEpo on villus diameter or villus length to crypt depth ratio.

ENTERAL VERSUS PARENTERAL rEpo EFFECTS

Epo concentrations and haematocrit values for the three experimental groups treated for one and two weeks are shown in fig 3. Trough Epo
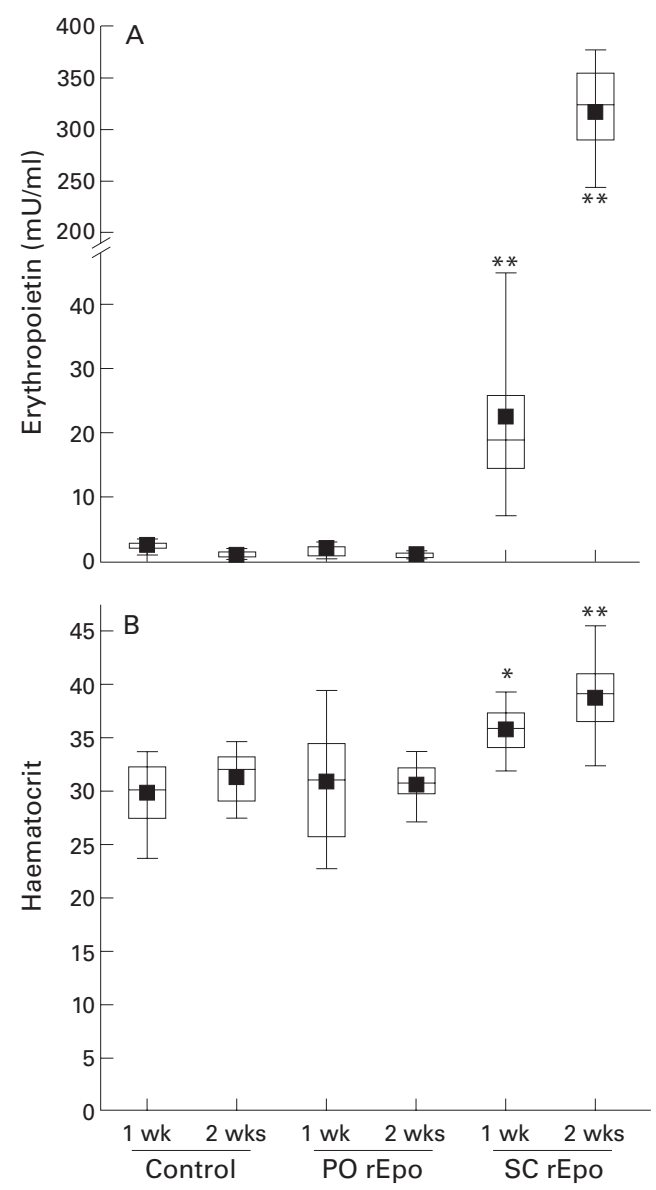

Figure 3 Erythropoietin (Epo) concentrations and haematocrit values from nursing rat pups. (A) Epo concentrations in the treatment groups: control (no exogenous recombinant human erythropoietin ( $r E p o)$ ), one and two weeks of therapy; $P O r E p o$ (dam received daily and two weeks of therapy; PO rEpo (dam received daily of therapy; and SC rEpo (pups received daily dose of 200 U/kg/day subcutaneously), one and two weeks of therapy. (B) Haematocrit values in the same treatment groups. Box plots as described in fig 1. ${ }^{*} p<0.05,{ }^{\star *} p<0.001$.

concentrations (24 (1) hours after the last injection) are shown for animals treated for one week while peak Epo concentrations (5 (1) hours after the last injection) are shown for animals treated for two weeks. Epo concentrations and haematocrit values in animals who received enteral rEpo were not different than controls, regardless of duration of therapy. In pups who received subcutaneous rEpo, both Epo concentrations and haematocrit values were higher than controls.

Table 1 Mean villus surface area, length, diameter and crypt depth

\begin{tabular}{llllll}
\hline & $\begin{array}{l}\text { Villus surface area } \\
\left(\mu m^{2}\right)\end{array}$ & $\begin{array}{l}\text { Villus length } \\
(\mu m)\end{array}$ & $\begin{array}{l}\text { Villus diameter } \\
(\mu m)\end{array}$ & $\begin{array}{l}\text { Crypt depth } \\
(\mu m)\end{array}$ & $\begin{array}{l}\text { Villi/mm } \\
\text { bowel }\end{array}$ \\
\hline AR control, $\mathrm{n}=55$ & $16120(585)$ & $312(8)$ & $51(1)$ & $56.9(1.3)$ & 13.4 \\
AR low dose rEpo (n=55) & $17950(725)$ & $354(8)+\dagger \dagger$ & $50(2)$ & $61.8(2.5)$ & $17.4 \dagger$ \\
AR high dose rEpo (n=39) & $21250(722)+\dagger+$ & $401(9)+1+$ & $53(1)$ & $54.9(1.6)$ & $15.4+\dagger$ \\
NP control (n=38) & $14800(1028)$ & $298(14)$ & $52(2)$ & $52.2(1.3)$ & 15.4 \\
NP rEpo treated dam (n=39) & $17400(716)^{\star}$ & $361(13)^{\star \star \star}$ & $48(2)$ & $49.8(1.6)$ & 17.3 \\
\hline
\end{tabular}

AR control, artificially raised pups; AR low dose rEpo, artificially raised pups, $200 \mathrm{U} / \mathrm{kg} /$ day enteral human recombinant erythropoietin (rEpo); AR high dose rEpo, artificially raised pups, $1000 \mathrm{U} / \mathrm{kg} /$ day enteral rEpo; NP control, nursing pups control; NP rEpo treated dam, nursing pups, dam treated with $200 \mathrm{U}$ rEpo/day intraperitoneally.

${ }^{\star} \mathrm{p}<0.05,{ }^{\star \star \star}{ }^{\mathrm{p}} \mathrm{p}<0.001$ compared with pups nursing from $\mathrm{rEpo}$ treated dam; $\dagger \mathrm{p}<0.05,+\dagger \mathrm{p}<0.01,+\dagger+\mathrm{p}<0.0001$ compared with artificially raised control pups.

Values are mean (SEM) or number. 
To determine if rEpo acted as a maturation factor, lactase, maltase, and sucrase activity was evaluated in weighed bowel segments from each group ( $n=6$ per group). As expected in rat pups of this age, little to no sucrase activity was present, and only minimal maltase activity, which was highest in the duodenum, and this did not differ between groups. Lactase activity was consistently highest in the distal jejunum/ ileum, and when measured as a function of grams of bowel weight, did not vary as a result of rEpo treatment.

Mean bowel length after one week of therapy was $50.9(0.7) \mathrm{cm}, 52.3(0.8) \mathrm{cm}$, and 51.4 $(0.6) \mathrm{cm}$ for control, enteral, and parenteral rEpo groups, respectively. When corrected for body size (bowel length $(\mathrm{cm})$ divided by weight (g)), mean bowel length/body weight was greater in the enteral rEpo group compared with controls $(\mathrm{p}<0.005)$ but not in the parenterally treated group $(\mathrm{p}=0.13) \quad(1.72$ (0.04), 1.91 (0.05), and $1.81(0.04) \mathrm{cm} / \mathrm{g}$, respectively). After two weeks of therapy, both rEpo treated groups had increased bowel
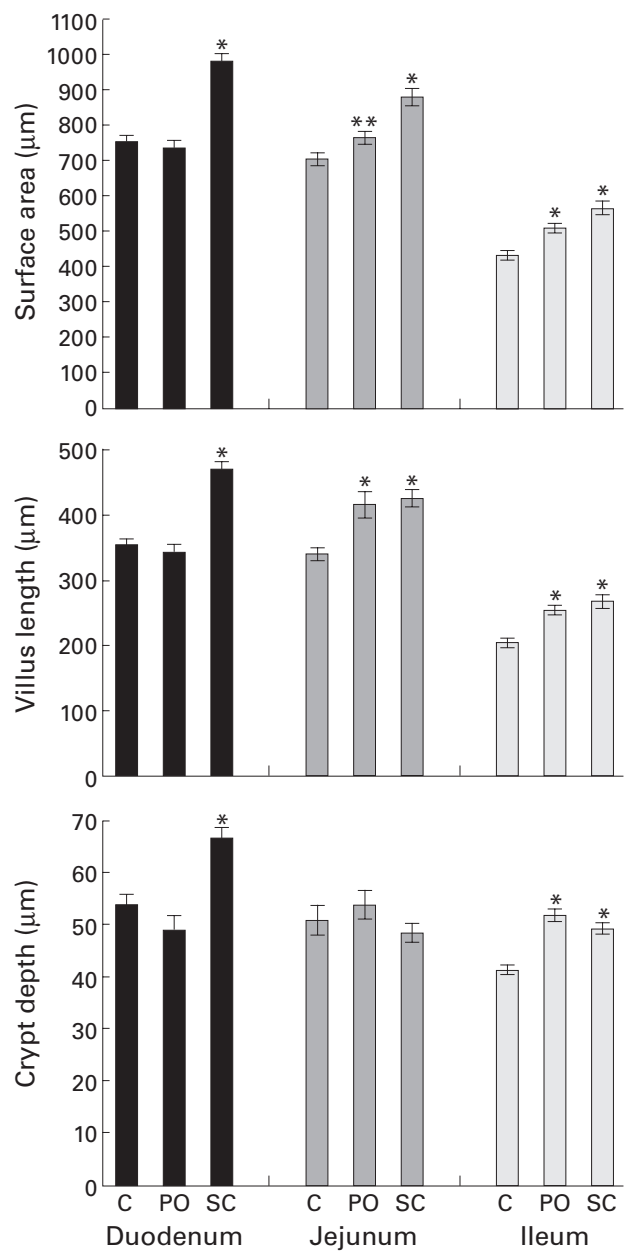

Figure 4 Morphometric measurements of the small bowel from control pups treated with no exogenous recombinant human erythropoietin ( $r E p o$ ) compared with enteral and parenterally treated pups. Measurements are mean (SEM) for villus surface area (top), villus length (middle), and crypt depth (bottom). Measurements for each treatment group (control $(C)$, no exogenous $r E p o ; P O$, dam received daily dose of 200 U rEpo intraperitoneally; SC, pups received daily dose of $200 \mathrm{U} / \mathrm{kg} /$ day rEpo subcutaneously) are compared by small bowel region (duodenum, jejunum, and ileum). ${ }^{\star} p<0.05,{ }^{\star}{ }^{\star} p<0.01$. length/g body weight compared with controls although the increase was most pronounced in the enterally treated group (1.68 (0.07) controls, $2.12(0.03)$ enteral rEpo, and 1.87 (0.04) parenteral rEpo; $\mathrm{p}<0.0001$ and 0.05 , respectively).

In the duodenum, villi from enterally treated pups were not different from controls but villi from pups receiving parenteral $\mathrm{rEpo}$ had greater surface area $(\mathrm{p}<0.0001,95 \%$ confidence interval (CI) 171-287), length $(\mathrm{p}<0.0001,95 \%$ CI 88-144), and crypt depth $(\mathrm{p}<0.0001,95 \%$ CI 6-20). In the jejunum, villus surface area was greater in both rEpo treated groups $(\mathrm{p}<0.05$, CI $8-112$ for enterally treated pups; $p<0.0001$, CI 111-239 for parenterally treated pups). Villus length was greater in both rEpo treated groups compared with controls $(p=0.000$, CI 33-121 for enterally treated pups; $\mathrm{p}<0.0001$, CI $55-118$ for parenterally treated pups). Villus diameter was greater in enterally treated pups $(p<0.01)$ but not in parenterally treated pups. The greatest differences were noted in the ileum with increased villus surface area, length, and crypt depth in both rEpo treated groups. Findings are summarised in fig 4 .

We postulated that one mechanism by which villus length might increase is by increased crypt cell division. Indeed, BrdU incorporation was significantly greater in the crypts and villi of animals receiving either enteral or parenteral rEpo compared with controls. These differences were more pronounced in distal than in proximal small bowel, with the most profound differences noted in the ileum. In the ileum, BrdU incorporation was noted in the villus tips as well as in the crypts of animals receiving $\mathrm{rEpo}$, as can be seen in fig 5 . Figure 6 shows the percentage of crypt cells which were BrdU positive in the duodenum, jejunum, and ileum from each treatment group.

\section{Discussion}

Growth factors are present in amniotic fluid and milk ingested during fetal and postnatal development. ${ }^{16-19}$ Some of these have been shown to have important trophic effects in the developing bowel. ${ }^{16}{ }^{19}{ }^{20}$ Other factors, such as Epo, are known to be present in these fluids but their roles have not yet been defined. ${ }^{12}$ The present studies have focused on the biological functions of Epo-R within the developing intestine.

The hypothesis that Epo can be enterally absorbed is supported by work from Carmichael and colleagues ${ }^{521} 22$ showing an increase in erythropoiesis in nursing rat pups following maternal phlebotomy, suggesting that Epo may be transmitted through mother's milk in rodents, although Epo concentrations in milk or pups were not measured. A pilot study addressing this issue in humans was performed in six premature infants. ${ }^{23}$ Each infant was given an oral dose of rEpo $1000 \mathrm{U} / \mathrm{kg} /$ day for 10 days with serum Epo concentrations measured at timed intervals following the oral dose. A small but statistically significant increase in circulating Epo concentrations was observed two hours following the dose but at 
no other time points. ${ }^{23}$ No increase in haematocrit or reticulocyte counts were observed. ${ }^{23}$ Unfortunately, rEpo was given in a non-protein containing buffered solution which may have significantly decreased the stability of the protein. ${ }^{124} \mathrm{~A}$ recent prospective study of 12 infants randomised to receive enteric $\mathrm{rEpo}(600 \mathrm{U} / \mathrm{kg} /$ week given three times a week) or placebo showed that enteric rEpo might result in increased erythropoiesis, although there was no difference in red blood cell transfusions required. ${ }^{25}$

In this study, we found no difference between serum Epo concentrations of artificially reared rat pups receiving one week of enteral $\mathrm{rEpo}$ in doses of $200 \mathrm{U} / \mathrm{kg} /$ day, 1000 $\mathrm{U} / \mathrm{kg} /$ day, or no exogenous enteral rEpo. Similarly, when pups were suckled, and received rEpo via rat milk for one or two weeks, no difference in haematocrit was noted compared with controls, although the haematocrit in a third group of pups treated daily with subcutaneous rEpo increased significantly during the experimental period, as did the haematocrit of the dams receiving rEpo. Thus it is unlikely that a significant role of Epo- $\mathrm{R}$ in rat bowel is absorption of enteric Epo, although we cannot rule out the possibility that small quantities of enterally dosed rEpo were absorbed. It is possible that the use of human rEpo in the rat model may have decreased enteric absorption compared with endogenous rat Epo, as rat and human Epo are only 80-82\% homologous. However, human and rat Epo show biological and immunological cross reactivity (as demonstrated by the increased haematocrit values in parenterally treated pups and rEpo treated dams), and hence this is an unlikely explanation for the low absorption of $\mathrm{rEpo}^{26}$

Our second hypothesis was that enterally dosed rEpo would (versus would not) have trophic effects in the small bowel. We clearly showed that rEpo, when given enterally for at least one week in either RMS or rat milk, significantly increases the length of the small bowel and also increases the absorptive surface

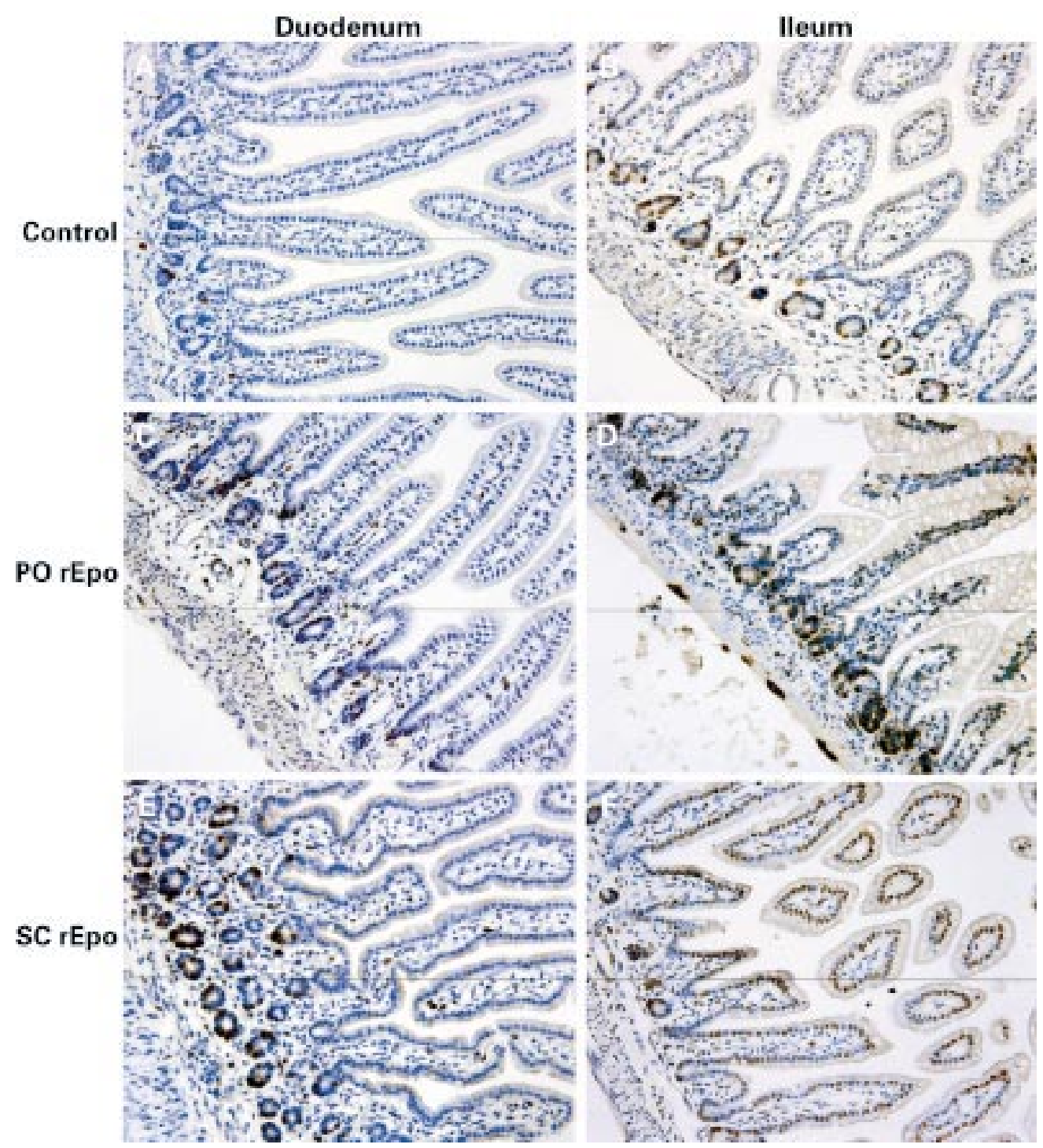

Figure 5 Bromodeoxyuridine (BrdU) incorporation in neonatal rat small bowel. All images were taken at an original magnification of 400x. $(A, B)$ Duodenum and ileum from control animals; $(C, D)$ duodenum and ileum from animals treated with recombinant human erythropoietin intraperitoneally ( $P O \mathrm{rEpo}$ ); and $(E, F)$ duodenum and ileum from subcutaneous rEpo (SC rEpo) treated animals. Brown staining shows BrdU positive cells. 


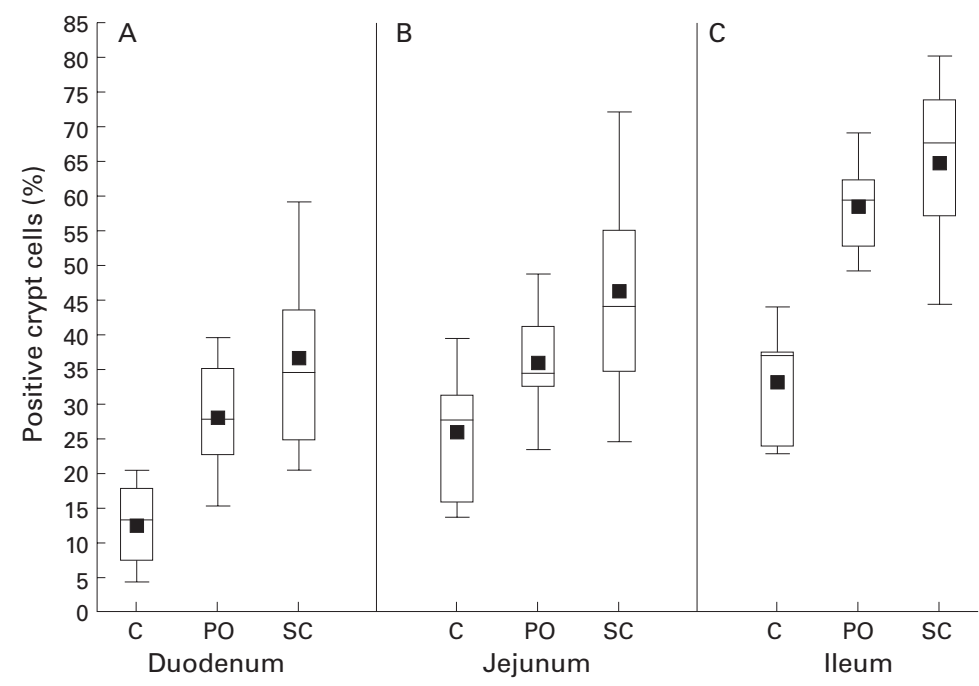

Figure 6 Bromodeoxyuridine (BrdU) positive crypt cells following no erythropoietin (Epo), enteral Epo, and parenteral Epo in the duodenum (A), jejunum (B), and ileum (C). Percentage of crypt cells with BrdU staining in each treatment group: control (no exogenous recombinant human erythropoietin (rEpo)), PO (dam received daily dose of 200 U rEpo intraperitoneally), and SC (pups received daily dose of $200 \mathrm{U} / \mathrm{kg} /$ day rEpo subcutaneously). Mean values and percentiles as described in fig 1.

area of microvilli, primarily by an increase in villus length. rEpo did not affect the specific activity of disaccharidases, as no differences in lactase, maltase, or sucrase activities were detected in any bowel segment between treatment groups. However, as the length of the small bowel increased with rEpo treatment, but the specific activity of the disaccharidase stayed the same, we can extrapolate that the total activity increased. This was most significant for lactase activity, followed by maltase activity, as minimal to no sucrase was present in any group.

Lastly, we hypothesised that the effects of $\mathrm{rEpo}$ in bowel would (versus would not) be route dependent. We found that rEpo, whether given enterally or parenterally, acts as a trophic factor in small bowel. There are however some route dependent differences: enterally dosed rEpo had a greater effect on small bowel length (normalised to body weight) than parenteral rEpo while both enteral and parenteral rEpo were associated with increased villus surface area. The effects of rEpo on villus length and surface area were most pronounced in the ileum. The precise mechanism by which this increase occurs is not clear but it appears to involve an increase in cell turnover, as demonstrated by our BrdU incorporation studies. The unusual finding of BrdU positive cells in the villi may reflect a combination of increased cell turnover and an increase in cell migration associated with $\mathrm{rEpo}$ administration. ${ }^{8}$

Epo-R are present on a variety of nonhaematopoietic cell types, including enterocytes, endothelial cells, smooth muscle cells, and neurones, cell types which are present in the developing bowel. ${ }^{7-9}{ }^{27-29}$ It is possible that Epo acts as a trophic factor on one or more of these cell types during growth and development. ${ }^{30}$ Enteral Epo is clearly not an essential requirement for postnatal bowel development, as human neonates are often fed non-Epo containing infant formulas and do well. Possible explanations include that circulating Epo is sufficient for normal bowel development or that Epo is not an essential growth factor for growth development. Unfortunately, the homozygous null mutation or "knockout" mouse models which are either Epo or Epo-R deficient do not survive gestation, dying at embryonic day 13.5 (approximately $65 \%$ of gestation). It has therefore not been possible to use these models to evaluate the effects of Epo on the growth and development of the bowel.

In summary, we have shown that enterally dosed rEpo is not absorbed in amounts sufficient to promote increased erythropoiesis but that it is associated with trophic effects in the developing neonatal rat intestine, increasing small bowel length and villus surface area. Parenterally dosed rEpo has the expected erythropoietic effects, as well as trophic effects in the small bowel. The potential clinical usefulness of these observations are apparent for such conditions as short bowel syndrome (resulting from necrotising enterocolitis or other bowel catastrophes), in which increasing the small bowel surface area would be of clinical benefit. The relevance of these findings to adults has not been studied and is unknown. Further investigation must be done to determine the clinical applicability of these important findings.

Supported by CAP award RR-00082 from the National Institutes of Health, and by the Children's Miracle Network.

Conflict of interest: S Juul is a consultant for Johnson and Johnson.

1 Kling PJ, Sullivan TM, Roberts RA, et al. Human milk as a potential enteral source of erythropoietin. Pediatr Res 1998;43:216-21.

2 Juul SE, Zhao Y, Dame JB, et al. Origin and fate of erythropoietin in human milk. Pediatr Res 2000;48:660-7.

3 Clapp JF III, Little KD, Appleby-Wineberg SK, et al. The effect of regular maternal exercise on erythropoietin in cord blood and amniotic fluid. Am F Obstet Gynecol 1995;172: 1445-51.

4 Richey SD, Ramin SM, Bawdon RE, et al. Markers of acute and chronic asphyxia in infants with meconium-stained amniotic fluid. Am f Obstet Gynecol 1995;172:1212-15.

5 Carmichael RD, LoBue J, Gordon AS. Neonatal erythropoiesis. II. Bone marrow and splenic erythropoietic activity: esis. II. Bone marrow and splenic erythropoietic activity: Data suggest erythropoietin
Endocr Regul 1992;26:143-9.

6 Carmichael RD, LoBue J, Gordon AS. Neonatal erythropoiesis. I. Peripheral blood erythropoietic parameters: Data suggest erythropoietin transfer via maternal milk. Endocr Regul 1992;26:83-8.

7 Juul SE, Yachnis AT, Christensen RD. Tissue distribution of erythropoietin and erythropoietin receptor in the developing human fetus. Early Hum Dev 1998;52:235-49.

8 Juul SE, Joyce AE, Zhao Y, et al. Why is erythropoietin present in human milk? Studies of erythropoietin receptors on enterocytes of human and rat neonates. Pediatr Res 1999;46:263-8.

9 Okada A, Kinoshita Y, Maekawa T, et al. Erythropoietin stimulates proliferation of rat-cultured gastric mucosal stimulates proliferation of rat-cu
cells. Digestion 1996;57:328-32.

10 Fatouros M, Dalekos GN, Mylonakis E, et al. Alterations in body weight, breaking strength, and wound healing in wistar rats treated pre- and postoperatively with erythropoietin or granulocyte macrophage-colony stimulating factor: Evidence of a previously unknown anabolic effect of erythropoietin? F Lab Clin Med 1999;133:253-9.

11 Ledbetter DJ, Juul SE. Erythropoietin and the incidence of necrotizing enterocolitis in infants with very low birth weight. F Pediatr Surg 2000;35:178-82.

12 Hall WG. Weaning and growth of artificially-reared rats. Science 1975;190:1313-15.

13 Austead N, Korsak RA, Bergstrom JD, et al. Milksubstitutes comparable to rat's milk; their preparation, composition, and impact on development and metabolism in the artificially reared rat. Br F Nutr 1989;61:495-518.

14 Philipps AF, Anderson GG, Dvorak B, et al. Growth of artifiPially fed infant rats: Effect of supplementation with insulin-
cialing cially fed infant rats: Effect of supplementation with in
like growth factor I. Am $\mathcal{F}$ Physiol 1997;272:R1532-9.

15 Rogers CT. Practical aspects of milk collection in the rat. Lab Anim 1994;29:450-5. 
16 Trahair JF, Wing SJ, Quinn KJ, et al. Regulation of gastrointestinal growth in fetal sheep by luminally administered insulin-like growth factor-I. F Endocrinol 1997;152 29-38.

17 Kimble RM, Breier BH, Gluckman PD, et al. Enteral IGF-I enhances fetal growth and gastrointestinal development in oesophageal ligated fetal sheep. F Endocrinol 1999;162:22735.

18 Marx CE, Vance BJ, Jarskog LF, et al. Nerve growth factor, brain-derived neurotrophic factor, and neurotrophin-3 levels in human amniotic fluid. Am f Obstet Gynecol 1999;181: $1225-30$

19 Okamura M, Kurauchi O, Itakura A, et al. Hepatocyte growth factor in human amniotic fluid promotes the migration of fetal small intestinal epithelial cells. $A m \mathcal{f}$ Obstet Gynecol 1998;178:175-9.

20 Carver JD, Barness LA. Trophic factors for the gastrointestinal tract. Clin Perinatol 1996;23:265-85.

21 Carmichael RD, Gordon AS, LoBue J. The effects of maternal phlebotomy and orally-administered erythropoietin (ep) on erythropoiesis in the suckling rat. Biol Neonate (ep) on erythropoi

22 Carmichael RD, Gordon AS, Lobue J. Effects of the hormone erythropoietin in milk on erythropoiesis in neonatal rats. Endocrinol Exp 1986;20:167-88.
23 Britton JR, Christensen RD. Enteral administration of recombinant erythropoietin to preterm infants. $\mathcal{F}$ Perinatol 1995;15:281-3.

24 Ohls RK, Christensen RD. Stability of human recombinant epoetin alfa in commonly used neonatal intravenous solutions. Ann Pharmacother 1996;30:466-8.

25 Ballin A, Bilker-Reich A, Arbel E, et al. Erythropoietin, given enterally, stimulates erythropoiesis in premature infants. Lancet 1999;353:1849.

26 Wen D, Boissel JP, Tracy TE, et al. Erythropoietin structure-function relationships: High degree of sequence homology among mammals. Blood 1993;82:1507-16.

27 Kanto WP Jr, Hunter JE, Stoll BJ. Recognition and medical management of necrotizing enterocolitis. Clin Perinatol 1994;21:335-46.

28 Yasuda Y, Nagao M, Okano M, et al. Localization of erythropoietin and erythropoietin-receptor in postimplantation mouse embryos. Dev Growth Differ 1993;35:711-22.

29 Anagnostou A, Liu Z, Steiner M, et al. Erythropoietin receptor mRNA expression in human endothelial cells. Proc Natl Acad Sci USA 1994;91:3974-8.

30 Campana WM, Misasi R, O'Brien JS. Identification of a neurotrophic sequence in erythropoietin. Int $\mathcal{F} \mathrm{Mol} \mathrm{Med}$ 1998;1:235-41.

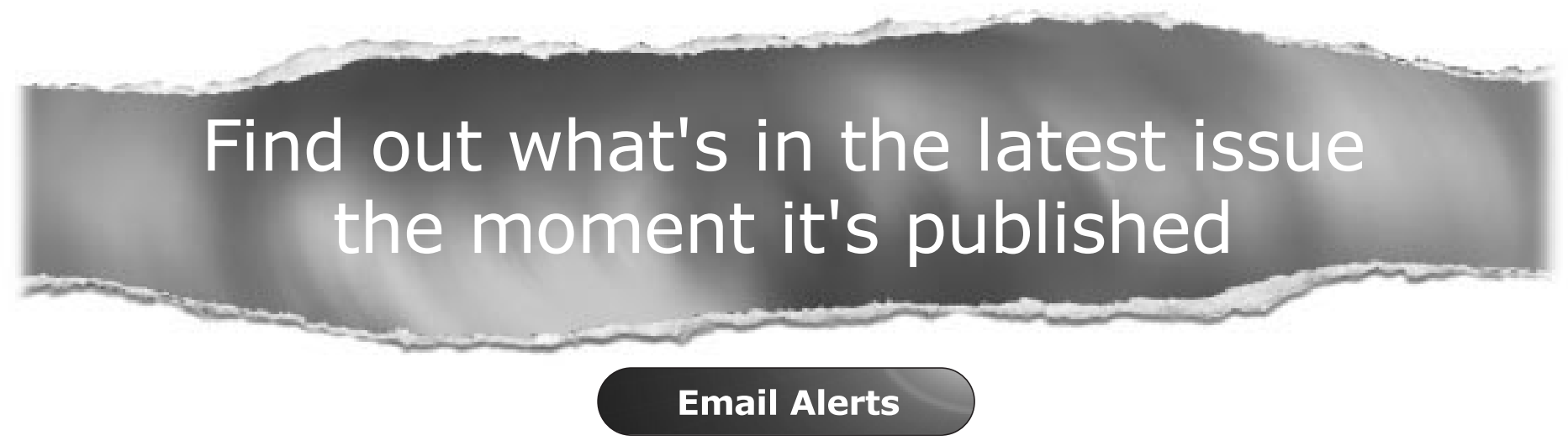

Sign up to receive the table of contents by email every month. You can select from three alerts: Table of Contents (full), TOC Awareness (notice only); Gut related announcements.

www.gutjnl.com 